\title{
Experimental study on production performance and reserves utilization law in carbonate gas reservoirs
}

\author{
Mengfei Zhou ${ }^{1,2,3}$ (1) Xuan Xu $\mathrm{Xu}^{3} \cdot$ Yuxuan Zhang $^{4} \cdot$ Chunyan Jiao $^{3} \cdot \mathrm{Yu} \mathrm{Tang}^{5} \cdot$ Zhiwei Bi $^{6}$
}

Received: 21 September 2021 / Accepted: 3 November 2021 / Published online: 22 November 2021

(c) The Author(s) 2021

\begin{abstract}
Carbonate gas reservoirs in China are rich in reserves. In the development process, there are many reserves with low permeability, low efficiency and low recovery degree. It is difficult to stabilize gas well production and prolong its life cycle. Under the condition of original water saturation $(S w)$ of $0 \%, 20 \%, 40 \%, 55 \%$ and $65 \%$, respectively, the physical simulation experiment of gas reservoirs depletion development was carried out by using long core multi-point embedded pressure measuring system. The long cores with average gas permeability of $2.300 \mathrm{mD}, 0.485 \mathrm{mD}$ and $0.046 \mathrm{mD}$ (assembled from 10 carbonate cores) were used to carry out this experiment. During the experiment, the pressure dynamics at different positions inside the long core and the gas production dynamics at the outlet were recorded in real time to reveal the production performance and reserves utilization law of carbonate gas reservoirs. The results show that the stable production period of tight reservoir in carbonate gas reservoirs is short, and the low production period is relatively long. The stable production time and recovery rate of gas reservoir increase with the increase of reservoir permeability and decrease with the increase of water saturation. The production of tight carbonate gas reservoirs with permeability less than $0.1 \mathrm{mD}$ is greatly affected by pore water, and the reservoir pressure distribution shows a steep pressure drop funnel, and the reserves far from well are rarely used. Therefore, the reserves far from well should be utilized by closing well to restore formation pressure balance, densifying well pattern or transforming reservoir. The variation range of water saturation in the development of carbonate gas reservoirs is influenced by reservoir permeability and water saturation, and closely related to formation pressure gradient in production process. It decreases with the increase of reservoir permeability and increases with the increase of original water saturation. The research results provide a theoretical basis for understanding the relationship between physical properties of carbonate gas reservoirs and production performance, reserves utilization law, and realizing balanced utilization, efficient development and long-term stable production of carbonate gas reservoirs.
\end{abstract}

Keywords Carbonate gas reservoirs $\cdot$ Permeability $\cdot$ Water saturation $\cdot$ Production performance $\cdot$ Formation pressure profile $\cdot$ Reserves utilization

\section{Introduction}

The global carbonate gas reservoirs are rich in resources and widely distributed, occupying an important position in the field of oil and gas exploration and development in

Xuan Xu

xuxuan69@petrochina.com.cn

$\triangle$ Zhiwei Bi

11196363@qq.com

1 School of Engineering Science, University of Chinese Academy of Sciences, Beijing 100049, China

2 Institute of Porous Flow and Fluid Mechanics, Chinese Academy of Sciences, Langfang 065007, China the world (Xie et al. 2009). Carbonate gas reservoirs also play an important role in the exploration and development of oil and gas resources in China. At present, large marine carbonate gas fields have been discovered in Tarim Basin, Sichuan Basin and Ordos Basin (Jia et al. 2013; Ma et al.

3 Research Institute of Petroleum Exploration and Development, PetroChina, Beijing 100083, China

4 No.1 Oil Production Plant, Xinjiang Oilfield Company, PetroChina, Karamay 834000, China

5 Institute of Exploration and Development, Southwest Oil and Gas Field Company, Petrochina, Chengdu 610041, China

6 Hebei Regional Geological Survey Institute, Langfang 065000, China

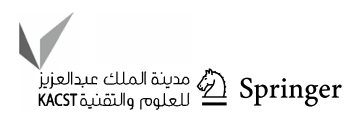


2017, 2019; Li et al. 2018, 2020; Mei et al. 2020). Gas reservoirs at home and abroad mainly rely on reservoir energy for depletion development and production, but in the middle and late stages of production of some water-bearing gas reservoirs with low permeability, problems of water production from gas wells and oil pressure approaching the delivery pressure of gas wells generally occur. Gas reservoirs with low permeability and low efficiency face great challenges such as low recovery degree, difficulty in stable production and in life cycle continuation (Yuan et al. 2005; Hu et al. 2019; He and Ou 2020). How to reasonably understand the production law of gas reservoirs, reveal the mechanism of reserves utilization, evaluate the degree of reserves utilization and predict the remaining reserves is of great significance for realizing the balanced utilization, efficient development and long-term stable production of carbonate gas reservoirs.

The existing research methods about reserves utilization mainly include fine description of gas reservoirs (Zhao et al. 2011; Yang et al. 2015), production dynamic analysis and numerical simulation (Wang et al. 2000; Ghanaei and Rahimpour 2010; Denney 2012; Ye and Ayala 2013; Zhang 2014; Tao 2018; Zhang et al. 2019a, b; Xie et al. 2020; Wang and Ayala 2020; Ruan et al. 2021) as well as conventional experiments (Lago et al. 2002; Bondino et al. 2011; Shen et al. 2021), but there are few experimental studies on production dynamic and reserves utilization mechanism in carbonate gas reservoirs development process. There are many theoretical studies on the propagation of pressure disturbance in the development of low permeability reservoirs, all of them believe that there is a threshold pressure gradient for oil and gas to flow in low permeability reservoir, and the pressure disturbance propagation has a dynamic boundary, which cannot reach infinity instantaneously like that of high permeability reservoir (Pascal 1981; Shi et al. 2011; Nobakht and Clarkson 2012). However, there is still a lack of experimental means to systematically study the influence of different reservoir permeability levels and different original water saturation on pressure disturbance propagation. At present, the physical simulation technology of gas reservoirs development is mainly to conduct the depletion development experiment after the full-diameter core or plunger core is pressurized and saturated, so as to obtain the instantaneous gas production and cumulative gas production, pressure dynamics and the change of water saturation before and after the experiment. Limited by equipment conditions and core size, only the pressure dynamics at both ends of the core can be obtained, and the pressure dynamics along the core cannot be obtained. In some experiments, multiple core holders are used in series or parallel to increase the pressure measuring point, but it is always unable to monitor the pressure change inside the core (Hu et al. 2016; Zhang et al. 2019a, b; Fang et al. 2019). In this paper, a new set of long core multi-point embedded pressure measuring physical simulation experiment method and device is independently developed to carry out the physical simulation experiment of the depletion development of carbonate gas reservoirs (Hu et al. 2020; Xu et al. 2020; Li et al. 2021). The pore pressure dynamics at different positions in the core and the gas production dynamics at the outlet end are monitored online and real time, revealing the production performance and reserves utilization mechanism of carbonate gas reservoirs, providing experimental technical support for the study of reserves utilization evaluation and mechanism in the process of gas reservoirs development.

\section{Experimental section}

\section{Experimental design}

Reservoir permeability and original water saturation are important factors affecting the production capacity of gas reservoirs (Lin et al. 2021), but there is still a lack of laboratory simulation experiments for quantitative study. Therefore, according to three types of permeability levels $(K>1 \mathrm{mD}, 1 \mathrm{mD}>K>0.1 \mathrm{mD}, K<0.1 \mathrm{mD}), 10$ carbonate plunger cores with similar permeability of $2.5 \mathrm{~cm}$ in diameter in $\mathrm{T}_{2} l_{1}^{1}$ gas reservoirs of Moxi gas field were selected, and the head and tail were spliced as long core group. Considering that the original water saturation of $\mathrm{T}_{2} l_{1}^{1}$ gas reservoirs is between 21.3 and $50.0 \%$, and the average water saturation is $44.0 \%$, in order to conform to the actual situation of the gas reservoirs and considering the comparability of experimental conditions, the water saturation of type I core group is set as $0 \%, 20 \%, 40 \%, 55 \%$ and $65 \%$, respectively. Type II and Type III core groups were set with water saturation of $0 \%, 20 \%, 40 \%$ and $55 \%$, respectively. Each core group was saturated with moist nitrogen to the initial formation pressure of $25 \mathrm{MPa}$ under different initial water saturation states.

Considering the difference of gas state between laboratory conditions and bottom hole, according to the gas motion equation, the average gas supply velocity of bottom hole gas layer is transformed into the gas seepage velocity of core ending face. After calculation, the typical gas well production allocation of low permeability and ultra-low permeability reservoirs is $3 \times 10^{4} \mathrm{~m}^{3} / \mathrm{d}$, which is converted to laboratory production allocation of $0.030 \mathrm{~L} / \mathrm{min}$. The typical gas well production allocation of tight reservoir is $1.5 \times 10^{4} \mathrm{~m}^{3} / \mathrm{d}$, which is converted to laboratory production allocation of $0.015 \mathrm{~L} / \mathrm{min}$.

The core group with different permeability is produced under the corresponding production allocation. The parameters and schemes of the core group in the physical simulation experiment of depletion development are shown in 
Table 1. After the stable production period, $0.003 \mathrm{~L} / \mathrm{min}$ was selected as the abandoned condition of gas reservoirs.

\section{Experimental equipment and process}

As shown in Fig. 1, A set of long core multi-point embedded pressure measuring system is independently developed. Multiple pressure measurement holes are arranged on the rubber sleeve inside the core holder, so as to online and dynamically detect the change of pore pressure along the core in the process of gas reservoirs depletion development experiment.

\section{Experimental procedure}

Step 1: Select several carbonate plunger cores with similar permeability, weigh them after saturated water, then air dry them naturally and weigh them in real time until the weight reaches the initial designed water saturation, form long core groups in series, and put them into long core multi-point embedded pressure measuring holder;

Step 2: Slowly saturate moist nitrogen from both ends of core group to design pressure through high pressure gas cylinder;

Step 3: Close the high pressure gas cylinder, check the sealing of the device to ensure the pressure stability;

Step 4: Slowly unscrew the valve at the outlet end of the core holder until the gas reaches the designed flow rate to simulate the depletion development of the gas reservoirs at a certain production allocation;

Step 5: The data acquisition system records the accumulated time, instantaneous gas flow, accumulated gas
Table 1 Physical simulation experiment scheme for depletion development
Fig. 1 Long core multi-point embedded pressure measuring physical simulation experiment system

\begin{tabular}{|c|c|c|c|c|c|c|}
\hline Type of core group & $\begin{array}{l}\text { Average } \\
\text { permeability } \\
(\mathrm{mD})\end{array}$ & $\begin{array}{l}\text { Average } \\
\text { porosity } \\
(\%)\end{array}$ & $\begin{array}{l}\text { Core } \\
\text { length } \\
(\mathrm{cm})\end{array}$ & $\begin{array}{l}\text { Average } \\
S w(\%)\end{array}$ & $\begin{array}{l}\text { Initial pore } \\
\text { pressure } \\
(\mathrm{MPa})\end{array}$ & $\begin{array}{l}\text { Experimental produc- } \\
\text { tion allocation (L/ } \\
\text { min) }\end{array}$ \\
\hline Type I & 2.300 & 13.200 & 49.5 & $\begin{array}{r}0 \\
20 \\
40 \\
55 \\
65\end{array}$ & 25 & 0.030 \\
\hline Type II & 0.485 & 9.867 & 49.6 & $\begin{array}{r}0 \\
20 \\
40 \\
55\end{array}$ & 25 & 0.015 \\
\hline Type III & 0.046 & 4.940 & 49.1 & $\begin{array}{r}0 \\
20 \\
40 \\
55\end{array}$ & 25 & 0.015 \\
\hline
\end{tabular}


production and pressure at each pressure measuring point in real time;

Step 6: When the gas flow at the outlet end of the core holder is displayed as 0 and the pressure of each pressure measuring point remains unchanged, the experiment is finished.

\section{Results and discussion}

\section{Gas production law of depletion development in water-bearing carbonate reservoir}

\section{Production dynamics and characteristics}

Figure 2 is the instantaneous gas production curve under different water saturation, which can directly reflect the production dynamic and stable production time of the gas reservoirs. The envelope area under the curve is the cumulative volume of gas production. Figure 3 is the diagram of the relationship between recovery degree and water saturation in stable production period. As shown in Figs. 2 and 3, under the same production allocation for the same type of reservoir, the stable production time, the cumulative gas production during the stable production period and the recovery degree during the stable production period decrease with the increase of water saturation. After the stable production period of Type I and II reservoir with permeability greater than $0.1 \mathrm{mD}$, the gas production rate decreases rapidly until production stops. Type III reservoir with permeability less than $0.1 \mathrm{mD}$ has short stable production period and relatively long low production period. Further analysis of Fig. 3 shows that the recovery degree of type I and II reservoir in stable production period is less affected by pore water. When water saturation reaches $55 \%$, the recovery degree in stable production period is still greater than $70 \%$. The recovery degree of Type III reservoir in stable production period is greatly affected by pore water. When the reservoir is not water-bearing, the recovery degree in stable production

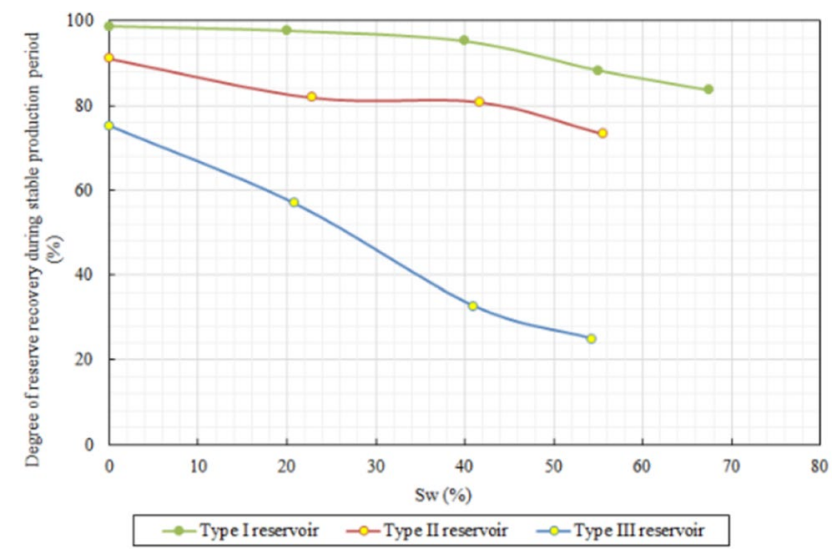

Fig. 3 Influence of water saturation on recovery degree of three types of reservoir in stable production period

period is $75.3 \%$; when the water saturation is $55 \%$, the recovery degree in stable production period decreases to $24.9 \%$.

In order to further compare and analyze the influence degree of water saturation on stable production time of reservoir with different permeability, and to exclude the influence of geological reserve difference under experimental conditions with different water saturation, the stable production time is normalized. The method is as follows:

$T s n=\frac{T s}{T s\left(s_{w}=0\right) \cdot\left(1-s_{w}\right)} \times 100 \%$

where $T s n$ is the normalized stable production time under a certain water saturation; $T s$ is the stable production time under such water saturation, $T s(S w=0)$ is the stable production time without pore water, and the unit of stable production time is min.

The relationship curve between stable production time and water saturation after normalization is shown in Fig. 4. It can be seen from Fig. 4 that the stable production time of reservoir with different permeability decreases with the increase of water saturation, but the degree of influence

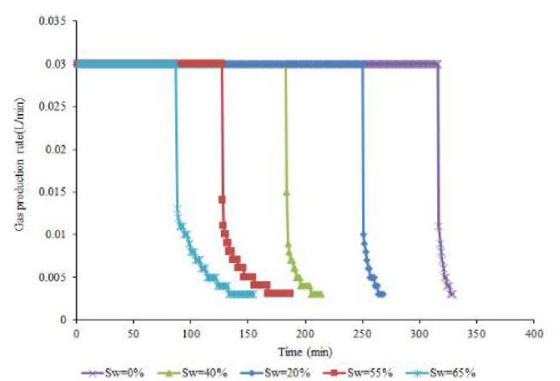

(a) Type I reservoir

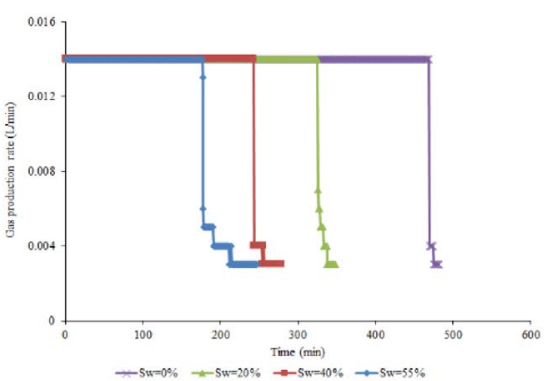

(b) Type II reservoir

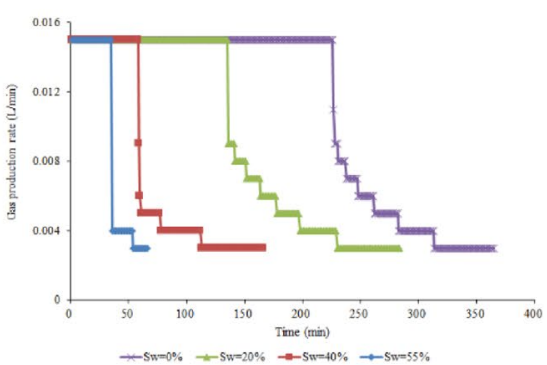

(c) Type III reservoir

Fig. 2 Instantaneous gas production curves of three types of reservoir with different water saturation 


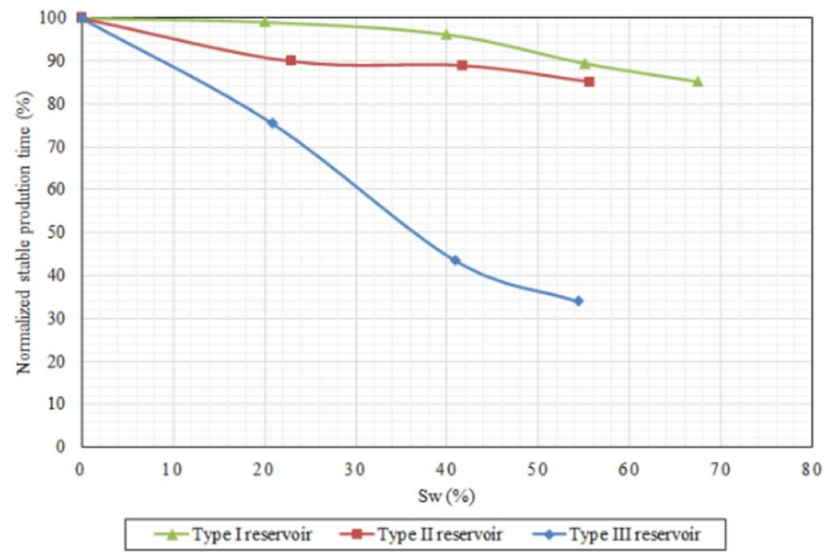

Fig. 4 Relationship between stable production time and water saturation of three types of reservoir after normalization

is significantly different. For type I reservoir with permeability greater than $1 \mathrm{mD}$, the stable production time is least affected by pore water, and the stable production time decreases gently with the increase of water saturation. When the water saturation is greater than $40 \%$, the stable production time decreases greatly. When the water saturation reaches $65 \%$, the stable production time can still reach $85.2 \%$ of the stable production time under anhydrous conditions. For type II reservoir with an average permeability of $0.485 \mathrm{mD}$, the influence of pore water on stable production time is greater than that of type I reservoir. The stable production time of type III reservoir with permeability less than $0.1 \mathrm{mD}$ is significantly affected by pore water. When the water saturation is less than $40 \%$, the stable production time decreases linearly. When the water saturation is $40 \%$, the stable production time decreases sharply by $56.5 \%$. When the water saturation is greater than $40 \%$, the stable production time decreases relatively slowly, but when the water saturation is $55 \%$, the stable production time is only $33.9 \%$ of the stable production time under anhydrous conditions.

The experimental understanding reveals the development characteristics of carbonate gas reservoirs with different permeability: for Type I and II reservoir, the stable production of gas wells is maintained under reasonable production allocation, the stable production time is long, and the recovery degree is high during the stable production period. For Type III reservoir with permeability less than $0.1 \mathrm{mD}$, the seepage channel is not developed, and the pore water further occupies the gas seepage channel, which leads to the difficulty of gas flow. Therefore, the pore water has a great influence on the recovery degree of tight reservoirs in stable production period, thus the reservoir reconstruction measures should be taken to increase the seepage channel, prolong the stable production time of gas wells and improve the recovery degree in stable production period.

\section{Recovery characteristics}

As shown in Figs. 2 and 5, for the same type of reservoir with the same production allocation, the production time, cumulative gas production and recovery under abandoned conditions decrease with the increase of water saturation. For the type I reservoir, when water saturation is 55\%, the recovery decreases to $95.8 \%$, and the recovery basically does not decrease anymore when water saturation continues to increase. For the type II reservoir, recovery decreased by $83.7 \%$ at a water saturation of $20 \%$, and the decrease was small as water saturation continued to increase. For Type III reservoir, pore water has a great influence on recovery, when water saturation is $0 \%, 20 \%, 40 \%$ and $55 \%$, the recovery is $90.5 \%, 77.9 \%, 49.2 \%$ and $36.3 \%$, respectively. It can be concluded that the recovery of carbonate type III reservoirs with permeability less than $0.1 \mathrm{mD}$ is significantly affected by water saturation. When water saturation is greater than $20 \%$, the recovery decreases sharply. When water saturation is greater than $40 \%$, the recovery decreases to less than $50 \%$. For carbonate reservoir of type I and II with permeability greater than $0.1 \mathrm{mD}$, the recovery is slightly affected by water saturation.

\section{Reserves utilization law of different types of reservoir}

During the experiment, the pressure along the core group was monitored in real time, and the utilization distance and the measured pressure were plotted into a curve. The outlet end of the core group is regarded as the bottom of the gas well. Through the dynamic pressure profile, it can intuitively reflect the real-time utilization of the internal reserves of the gas reservoirs in the process of gas well depletion development and provide important experimental methods and analytical means for analyzing the law of reserves utilization.

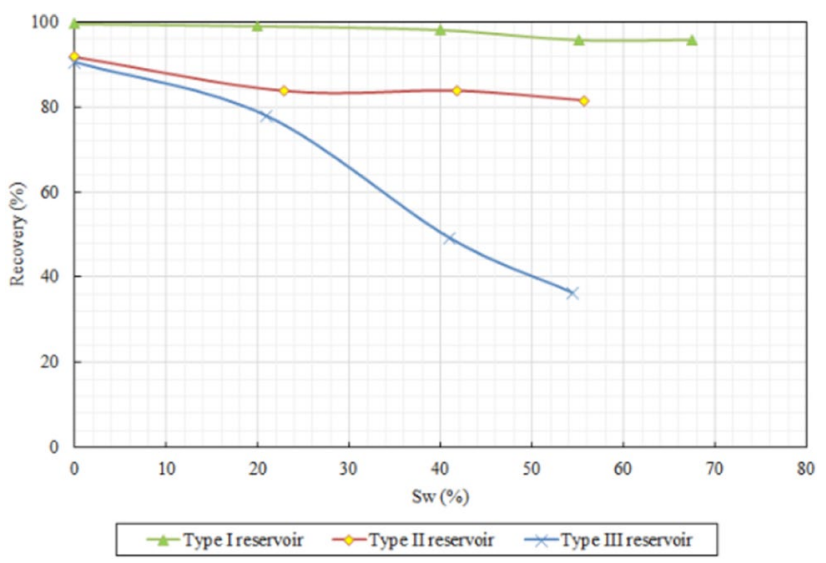

Fig. 5 Relationship of recovery and water saturation for three types of reservoir

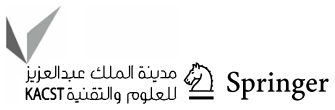


Assuming that the gas well is in homogeneous carbonate reservoir with equal thickness and gas saturation, the experimental method and pressure profile designed in this paper, as shown in Fig. 6, can reflect the utilization range of reserves and pressure drop characteristics in the process of gas reservoirs depletion development and compare the degree of reserves utilization by area method.

\section{Effect of reservoir permeability}

Taking type II and type III reservoir as examples, by comparing the pressure profiles of $10 \mathrm{~min}, 30 \mathrm{~min}, 90 \mathrm{~min}$ and $180 \mathrm{~min}$ with the same production rate of $0.015 \mathrm{~L} / \mathrm{min}$ under the condition of $40 \%$ water saturation (Fig. 7), the reserves utilization law of carbonate reservoir with different permeability is intuitively shown. The comparative analysis of pressure profiles shows that the pressure variation characteristics of these two types of reservoir are obviously different in the process of depletion development of water-bearing gas reservoirs, indicating that there are significant differences in the law of reserves utilization: (1) For type II reservoir with permeability greater than $0.1 \mathrm{mD}$, the pressure drop funnel is relatively flat, indicating that the reserves utilization is relatively balanced, and the utilization range has been spread to the boundary of the rock body when time is $10 \mathrm{~min}$, and the utilization range is large and limited by the boundary of the rock body; (2) For type III reservoir with permeability less than $0.1 \mathrm{mD}$, the pressure drop spreads slowly from the near wellbore to the periphery, and the pressure profiles present a pressure drop funnel with steep concave surface. The rock boundary is still basically not used passively after 30 min of production; (3) Under the same production allocation conditions and the same production time of gas wells,

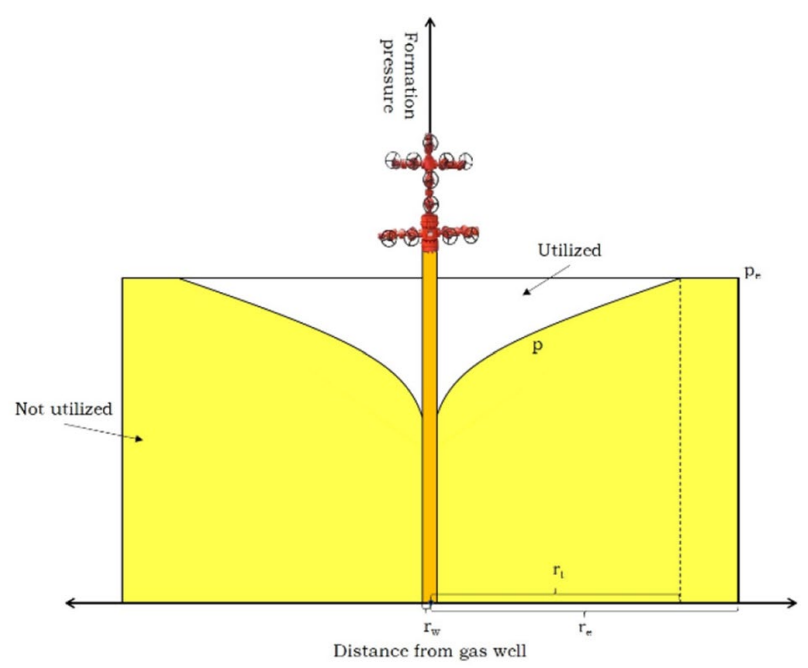

Fig. 6 Schematic diagram of evaluation method of reserves utilization in different parts of gas reservoirs it can be seen by area method that the reserves utilization of type III reservoir is significantly smaller than that of type II reservoir.

By comparing the pressure profiles of the three types of reservoir with different recovery degrees at $55 \%$ water saturation (Fig. 8), it is found that the recovery degree of the type I reservoir is the highest, reaching $95.8 \%$. For type II reservoir, the recovery degree reaches $81.5 \%$. The recovery degree of type III reservoir is significantly affected by pore water, and the concave surface of pressure drop funnel is very steep. Until the abandoned condition is reached, the distal reserves far from gas wells are still basically unused, and the recovery degree is only $36.3 \%$.

\section{Effect of reservoir water saturation}

As shown in Fig. 9, under abandoned conditions, the pressure profiles of three types of reservoir under different water saturations are compared. For the same type of reservoir, the higher the water saturation is, the steeper the concave surface of the pressure drop funnel is, indicating that the more uneven the reserves utilization is, the lower the reserves utilization degree calculated by the area method is. Under the same water saturation state, the lower the reservoir permeability is, the steeper the concave surface of the pressure drop funnel is, and the more difficult the reserves utilization is. When there is no pore water in the reservoir, the three types of reservoir are completely exploited. When the water saturation is higher than $40 \%$, the distal reserves of type III reservoir are almost not utilized. No matter the water saturation is high or low, the utilization degree of type I and II reservoir is higher, more than $81.5 \%$. Therefore, it can be considered that the influence of pore water on the development of carbonate reservoir with permeability greater than $0.1 \mathrm{mD}$ is small, because the reservoir permeability is high, and the gas flow ability is strong, so the reservoir pressure decreases synchronously, and the reservoir is balanced. Pore water has a great influence on tight carbonate reservoir with permeability less than $0.1 \mathrm{mD}$, and it is difficult to utilize remote reserves when water saturation is high, which is the main reason for low stable production capacity and small controlled reserves of single well in some gas reservoirs. It is difficult to achieve economic production without fracturing stimulation measures.

At present, most of the gas reservoirs are facing the problem of low oil pressure in the middle and later stage of production. For example, oil pressure of $96 \%$ of the production wells in the west of $\mathrm{T}_{2} l_{1}^{1}$ gas reservoirs at the end of 2018 was lower than $5.0 \mathrm{MPa}$ (close to the delivery pressure of 4.5 MPa), and the production accounted for $85 \%$ of the total production in the West. In order to explore the causes of low oil pressure but low recovery in gas wells, the pressure profiles in the depletion development process of long 


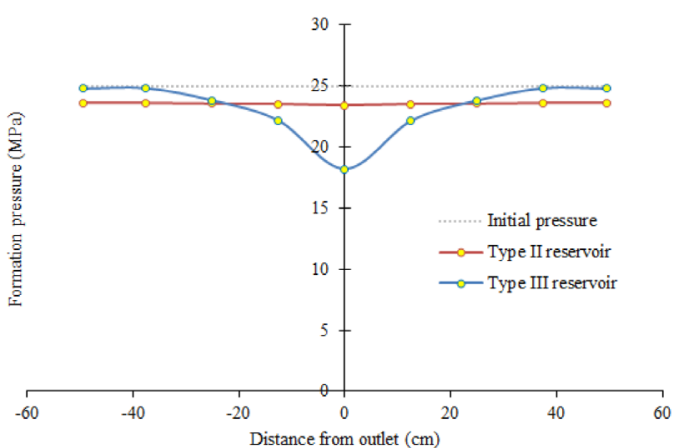

(a) time $=10 \mathrm{~min}$

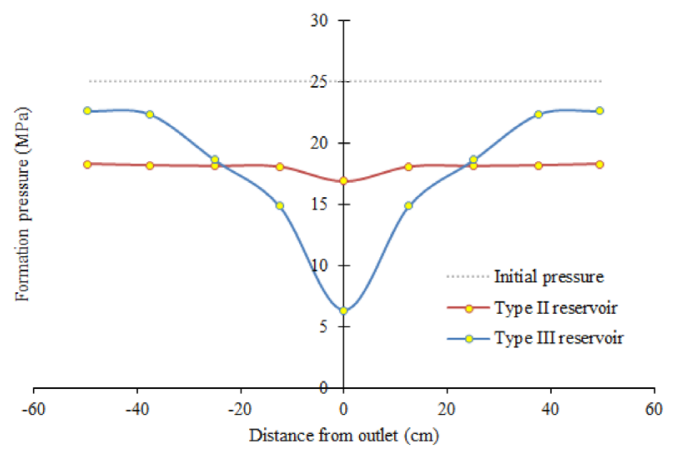

(c) time $=90 \mathrm{~min}$

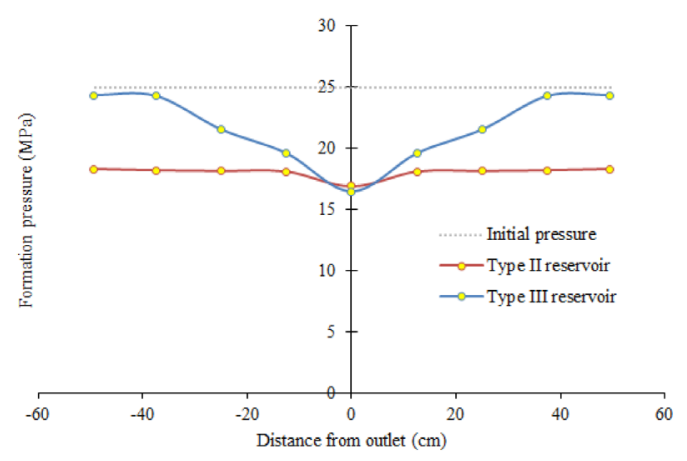

(b) time $=30 \mathrm{~min}$

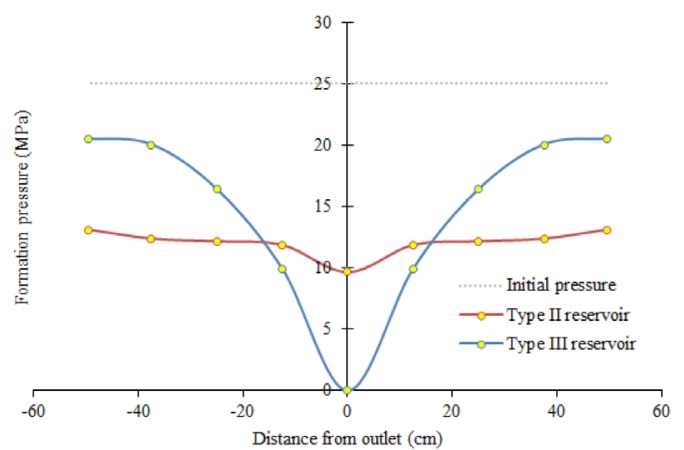

(d) time $=180 \mathrm{~min}$

Fig. 7 Pressure profiles of type II and III reservoir $(S w=40 \%)$

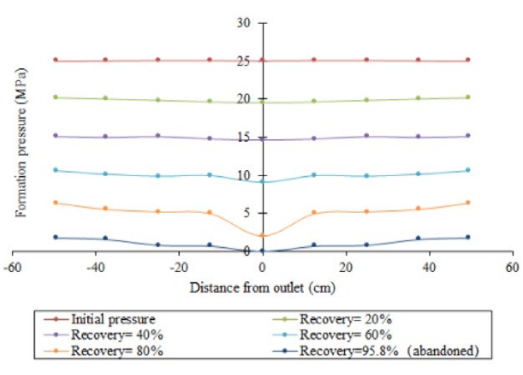

(a) Type I reservoir

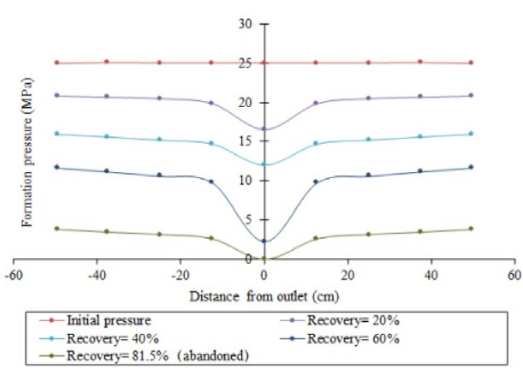

(b) Type II reservoir

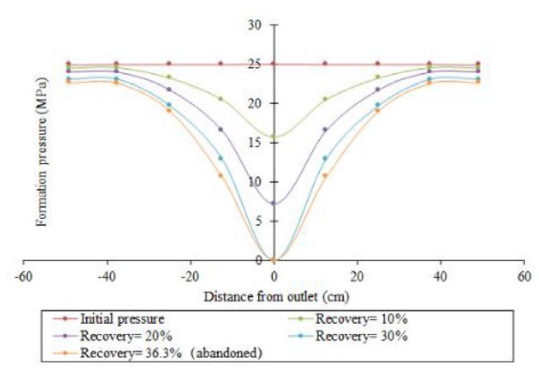

(c) Type III reservoir

Fig. 8 Pressure profiles of three types of reservoir $(S w=55 \%)$

carbonate core with permeability of $0.046 \mathrm{mD}$ and water saturation of $55 \%$ were selected for in-depth analysis. As shown in Fig. 10, the outlet pressure of the core is regarded as the oil pressure of the gas well in the physical simulation experiment. When the oil pressure of the gas well decreases from 25 to $5 \mathrm{MPa}$, the recovery degree is only $9.4 \%$. From the pressure profiles, it is found that the pressure in the nearwell area decreases rapidly, but the pressure in the far-well area decreases very little, indicating that the oil pressure of the gas well decreases rapidly in the tight gas reservoirs with high water saturation, but the reserves utilization is extremely uneven and the recovery degree is very small. When the oil pressure of the gas well continues to drop to $4.5 \mathrm{MPa}$, the recovery percent increases only from 9.4 to $10.8 \%$, the recovery percent reaches $24.8 \%$ at the end of the stable production period, and the recovery reaches $30.9 \%$ when the abandoned condition is reached. Although the recovery rate of the gas well increases by $21.5 \%$ from 


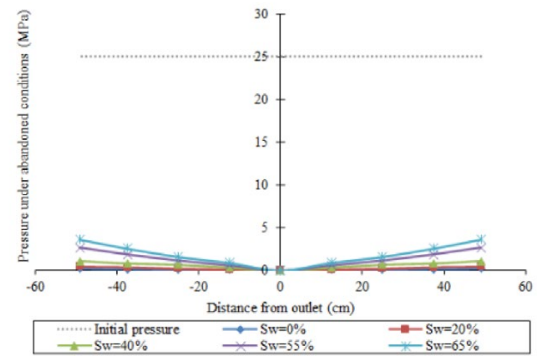

(a) Type I reservoir

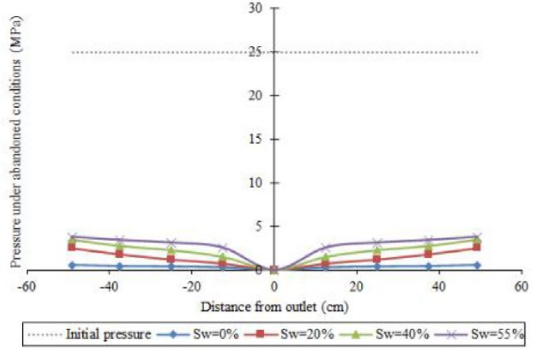

(b) Type II reservoir

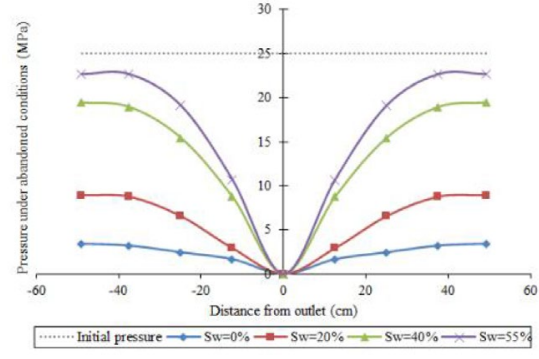

(c) Type III reservoir

Fig. 9 Pressure profiles under abandoned production conditions

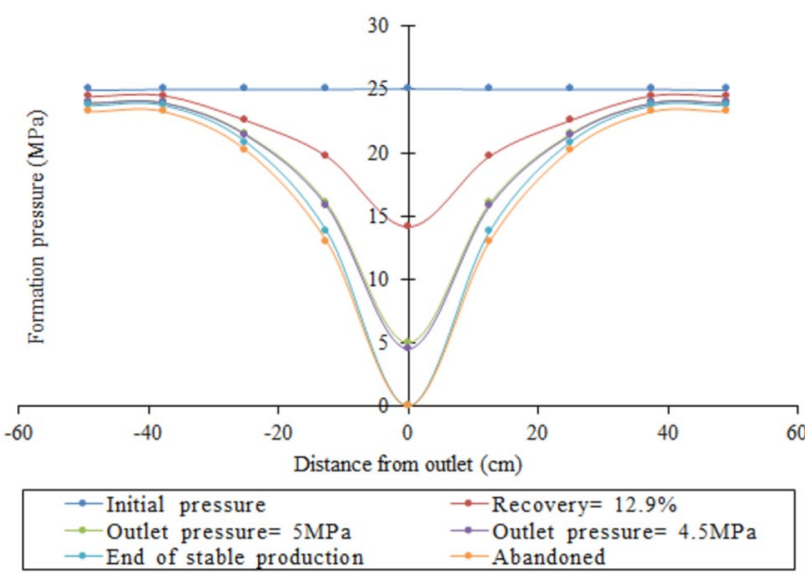

Fig. 10 Pressure profiles of type III reservoir $(S w=55 \%)$

$5 \mathrm{MPa}$ to abandoned conditions, the pressure drop range is only near the well area, and there is almost no pressure drop at the far end. Therefore, it is considered that when the tight carbonate gas reservoirs is developed to the point where the oil pressure of the gas well is close to the delivery pressure, the recovery degree is very low, and the reserves at the far end of the gas well are almost not utilized. It is necessary to shut in the well to restore the balance of formation pressure distribution, or to fully utilize the reserves through infill well or reservoir transformation.

\section{Variation characteristics of water saturation before and after gas reservoirs production}

The cores were weighed before and after the depletion development experiment, and the change of water saturation before and after the gas reservoirs production was evaluated by subtracting the core water saturation after the experiment from the core water saturation before the experiment. As shown in Fig. 11, before and after the experiment, the change of water saturation of type III reservoir is the largest, and the change of water saturation of type II reservoir is

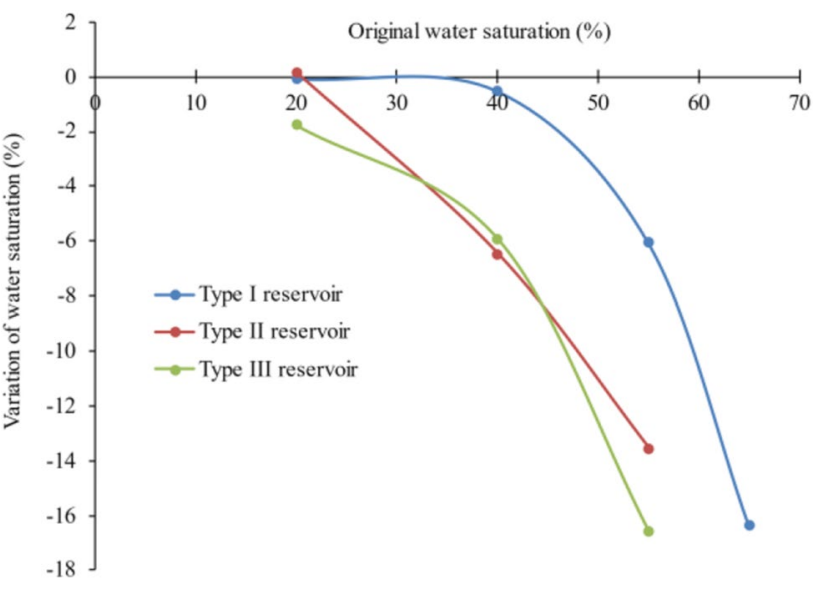

Fig. 11 Changes of water saturation in core group before and after experiment

the smallest. For the same type of reservoir, the higher the original water saturation, the greater the change of water saturation before and after the experiment. Combined with the variation characteristics of water saturation before and after the experiment of three types of reservoir and the above pressure profiles analysis, it is known that the variation characteristics of water saturation before and after gas reservoirs production are closely related to the formation pressure gradient. For the same type of reservoir, the smaller the original water saturation of the gas reservoirs is, the smoother the formation pressure profile is in the production process, and the smaller the pressure gradient is, the smaller the displacement effect of gas phase to pore water in the development process is, and the smaller the water saturation decreases. Under the same water saturation, the smaller the reservoir permeability is, on the one hand, the smaller the seepage channel is; on the other hand, the greater the pressure gradient in the production process is, the greater the displacement effect of gas phase to pore water in the production process is, and the greater the water saturation decreases. 


\section{Conclusions}

Based on the production performance, pressure profiles and water production characteristics of long core multi-point embedded pressure measuring depletion development physical simulation experiment, the reserves utilization law and production performance of water-bearing carbonate gas reservoirs are clarified, and the reserves utilization mechanism is revealed. The following conclusions are drawn:

(1) The stable production period of tight reservoir in carbonate gas reservoirs is short, and the low production period is relatively long. The stable production time and recovery of gas reservoirs increase with the increase of reservoir permeability and decrease with the increase of water saturation.

(2) The production of carbonate gas reservoirs with permeability greater than $0.1 \mathrm{mD}$ is less affected by pore water, and the range of reserves utilization is large. The production of tight carbonate gas reservoirs with permeability less than $0.1 \mathrm{mD}$ is greatly affected by pore water, the reservoir pressure distribution presents a steep pressure drop funnel, and the reserves far from well are rarely utilized. Therefore, the reserves utilization range should be expanded by closing well to restore formation pressure balance, densifying well pattern or transforming reservoir.

(3) The variation characteristics of water saturation during the development of carbonate gas reservoirs are affected by reservoir permeability and water saturation, which are closely related to the formation pressure gradient in the production process. The higher the original water saturation of gas reservoirs is, the greater the formation pressure gradient in the process of depletion development, the stronger the effect of gas driving water, and the greater the decline of water saturation. Under the same water saturation, the lower the reservoir permeability is, the greater the formation pressure gradient in the process of depletion development, the stronger the effect of gas driving water is, and the greater the decline of water saturation is.

Funding The work was financially supported by the National Natural Science Foundation of China (Grant No.51704326) and Major Science and Technology Projects of CNPC (Grant No.2016E-0607).

Data availability The data used to support the findings of this study are available from the corresponding author upon request.

\section{Declarations}

Conflict of interest All authors declare that there is no conflict of interest in this article.
Open Access This article is licensed under a Creative Commons Attribution 4.0 International License, which permits use, sharing, adaptation, distribution and reproduction in any medium or format, as long as you give appropriate credit to the original author(s) and the source, provide a link to the Creative Commons licence, and indicate if changes were made. The images or other third party material in this article are included in the article's Creative Commons licence, unless indicated otherwise in a credit line to the material. If material is not included in the article's Creative Commons licence and your intended use is not permitted by statutory regulation or exceeds the permitted use, you will need to obtain permission directly from the copyright holder. To view a copy of this licence, visit http://creativecommons.org/licenses/by/4.0/.

\section{References}

Bondino I, McDougall SR, Hamon G (2011) Pore-scale modelling of the effect of viscous pressure gradients during heavy oil depletion experiments. J Can Pet Technol 50(2):45-55

Denney D (2012) Shale-gas reserves estimation: multiple declinecurve-analysis models. J Pet Technol 64(11):144-148

Fang F, Gao S, Liu H, Xiao Q, Ma X, Zhang C (2019) Experimental simulation study on water invasion law of gas reservoir with multiwell development. Res Explor Lab 38(05):42-45

Ghanaei E, Rahimpour MR (2010) Evaluation of orthogonal collocation and orthogonal collocation on finite element method using genetic algorithm in the pressure profile prediction in petroleum reservoirs. J Pet Sci Eng 74:41-50

He X, Ou J (2020) The agent technologies for efficient development of Moxi T2 111 gas reservoir. J Southwest Pet Univ, Sci Technol Ed 42(04):144-154

Hu Y, Li X, Wan Y, Jiao C, Xu X, Guo C, Jing W (2016) The experimental study of water invasion mechanism in fracture and the influence on the development of gas reservoir. Nat Gas Geosci 27(05):910-917

Hu Y, Peng X, Li Q, Li L, Hu D (2019) Progress and development direction of technologies for deep marine carbonate gas reservoirs in the Sichuan Basin. Nat Gas Ind 39(09):48-57

Hu Y, Mei Q, Wang J, Chen Y, Xu X, Jiao C, Guo C (2020) Optimization of well pattern infilling in tight sandstone gas reservoir. Nat Gas Geosci 31(09):1326-1333

Jia A, Yan H, Guo J, He D, Cheng L, Jia C (2013) Development characteristics for different types of carbonate gas reservoirs. Acta Pet Sin 34(05):914-923

Lago M, Huerta M, Gomes R (2002) Visualization study during depletion experiments of venezuelan heavy oils using glass micromodels. J Can Pet Technol 41(01):41-47

Li X, Guo Z, Hu Y, Luo R, Su Y, Sun H, Liu X, Wan Y, Zhang Y, Li L (2018) Efficient development strategies for large ultra-deep structural gas fields in China. Pet Explor Dev 45(01):111-118

Li X, Guo Z, Hu Y, Liu X, Wan Y, Luo R, Sun Y, Che M (2020) High-quality development of ultra-deep large gas fields in China: challenges, strategies and proposals. Nat Gas Ind 40(02):75-82

Li X, Hu Y, Xu X, Jiao C (2021) Research and application of tight sandstone gas development mechanism. Science Press, Beijing, pp 121-150

Lin W, Xiong S, Liu Y, He Y, Chu S, Liu S (2021) Spontaneous imbibition in tight porous media with different wettability: pore-scale simulation. Phys Fluids 33(3):032013

Ma X (2017) A golden era for natural gas development in Sichuan Basin. Nat Gas Ind 37(02):1-10 
Ma X, Yang Y, Wen L, Luo B (2019) Distribution and exploration direction of medium- and large-sized marine carbonate gas fields in Sichuan Basin, SW China. Pet Explor Dev 46(01):1-13

Mei Q, Zou C, Yang S, Yang SL, Zhao Y, Zheng W (2020) The influence of pore structure and heterogeneity on development of carbonate gas reservoir. Nat Gas Geosci 31(12):1757-1765

Nobakht M, Clarkson CR (2012) A new analytical method for analyzing linear flow in tight/shale gas reservoirs: constant-flowing-pressure boundary condition. SPE Reserv Eval Eng 15(3):370-384

Pascal H (1981) Nonsteady flow through porous media in the presence of a threshold gradient. Acta Mech Sin 39:207-224

Ruan J, Pang J, Yuan Q, Yi J, Ou J (2021) Variation rules of driving energy of deep aqueous carbonate gas reservoirs in Moxi block of Anyue gas field. Spec Oil Gas Reserv 28(02):83-88

Shen W, Li X, Ma T, Cai J, Lu X, Zhou S (2021) High-pressure methane adsorption behavior on deep shales: experiments and modeling. Phys Fluids 33(6):063103

Shi A, Wang X, Luo E, Bi M (2011) Propagation of pressure disturbance in low permeability formation. Spec Oil Gas Reserv 18(4):80-82

Tao X (2018) The studying about recovery of shan 45 field in Jingbian gas reservoir. Dissertation, China University of Petroleum

Wang Y, Ayala LF (2020) Explicit determination of reserves for variable-bottomhole-pressure conditions in gas rate-transient analysis. SPE J 25:369-390

Wang D, Wang H, Li Y (2000) Evaluation of producing percent of difficult-to-recover reserves in Changqing gas field. Nat Gas Ind 20(05):64-66

Xie J, Huang C, Wang X (2009) Distribution features of proved reserves of carbonate oil and gas pools in China. Mar Origin Pet Geol 14(02):24-30

Xie S, Wu Y, Zhang J, Jiao Y, He L (2020) Technical countermeasures of enhance gas recovery in low permeability carbonate gas reservoir. Sci Technol Eng 20(06):2231-2236
Xu X, Mei Q, Chen Y, Han Y, Tang H, Jiao C, Guo C (2020) Experimental analysis method for water invasion and development performance of gas reservoir. Nat Gas Geosci 31(10):1355-1366

Yang G, Wang H, Shen H, Yang Y, Jia S, Chen W, Zhu H, Li Y (2015) Characteristics and exploration prospects of Middle Permian reservoirs in the Sichuan Basin. Nat Gas Ind 35(07):10-16

Ye P, Ayala LF (2013) Straightline analysis of flow rate vs. cumulativeproduction data for the explicit determination of gas reserves. $\mathbf{J}$ Can Pet Technol 52(4):296-305

Yuan S, Hu Y, Luo K (2005) State of the art, challenges and countermeasures of natural gas development in China. Pet Explor Dev 32(06): $1-6$

Zhang Y (2014) Study on well pattern optimization and dynamic law in $\mathrm{s}$ gas field. Dissertation, Southwest Petroleum University

Zhang J, Li X, Chen Z, Li Q, Li G, Lv T (2019a) Numerical simulation of the improved gas production from low permeability hydrate reservoirs by using an enlarged highly permeable well wall. J Pet Sci Eng 183:106404

Zhang J, Li X, Gao S, Ye L, Liu H, Zhu W, Fang F (2019b) Water production mechanism of tight sandstone gas reservoir and its influence on percolation capacity. Nat Gas Geosci 30(10):1519-1530

Zhao W, Xu C, Wang T, Wang H, Wang Z, Bian C, Li X (2011) Comparative study of gas accumulations in the Permian Changxing reefs and Triassic Feixianguan oolitic reservoirs between Longgang and Luojiazhai-Puguang in the Sichuan Basin. Chin Sci Bull $56: 2404-2412$

Publisher's Note Springer Nature remains neutral with regard to jurisdictional claims in published maps and institutional affiliations. 